\title{
Pendampingan Pelatihan Speakerpreneur dan MC
}

\author{
Andiwi Meifilina $^{1^{*}}$, Bina Andari ${ }^{2}$ \\ ${ }^{1}$ Ilmu Komunikasi, Universitas Islam Balitar, Jl. Majapahit No.2- 4, Kota Blitar, Indonesia, 66137 \\ ${ }^{2}$ Ilmu Administrasi Niaga, Universitas Islam Balitar, Jl. Majapahit No.2- 4, Kota Blitar, Indonesia, 66137 \\ Correspondence: andiwimeifilina@unisbablitar.ac.id \\ Received: 30 Juni 2021 - Revised: 01 Agustus 2021 - Accepted: 16 Agustus 2021

\begin{abstract}
Abstrak. Kemampuan intelektual seseorang tidak bisa menjamin kesuksesan seseorang tersebut, namun bagaimana mereka bisa "menjual" diri mereka kepada publik. Kemampuan "menjual" ini tidak hanya tergantung pada cara berkomunikasi di depan publik tetapi juga bagaimana seseorang bisa membawa diri mereka agar bisa diterima oleh publiknya. Berangkat dari hal tersebut tujuan dari kegiatan ini yaitu untuk memberikan pelatihan tentang tata cara menjadi MC yang handal yang mampu menjual bakat MC nya baik untuk acara hiburan maupun formal. Kegiatan ini diharapkan akan dijadikan pemicu semangat santri untuk mau belajar dan berlatih mempersiapkan dirinya tampil di acara pondok pesantren bahkan di masyarakat. Kegiatan pengabdian masyarakat ini dipandang cukup berhasil menambah keberanian dan percaya diri santrisantri Pondok Pesantren Tarbiyatus Sholihin ketika tampil MC di acara-acara pondok maupun acara di luar kegiatan pondok, pasalnya terdapat banyak peningkatan yang terjadi pada mereka.
\end{abstract}

Kata kunci: MC, speakerpreneur, santri, ponpes.

Citation Format: Meifilina, A. \& Andari, B. (2021). Pendampingan Pelatihan Speakerpreneur dan MC. Prosiding Seminar Nasional Abdimas Ma Chung (SENAM), 98-105. 


\section{PENDAHULUAN}

Master of Ceremony atau yang lebih dikenal dengan MC merupakan seni pembawaan memandu acara dengan bahasa lisan yang efektif dan vocal yang jelas baik intonasi, kecepatan dalam bicara, penekanan kalimat, dan artikulasi yang kemudian juga didukung oleh penggunaan bahasa lisan maupun tulisan dan gesture tubuh (Hutomo, 2019). Seorang Master of Ceremony juga disebut sebagai seniman kata-kata dan seniman bahasa tubuh.

Jika dikhususkan pada bidang keagamaan maka dapat diketahui bersama bahwa di tengah masyarakat seni pembawaan MC sudah enggan di minati oleh kaum remaja. Saat ini remaja harus disadarkan bahwa keberanian belajar MC (Master of Ceremony) dan tampil sangat minim dan lemah sekali. Tradisi-tradisi baik yang pada masa orang tua dahulu mulai luntur dan ditinggalkan yaitu kesemangatan dan keberanian belajar MC (Master of Ceremony). Belum lagi di era saat ini hampir setiap saat remaja lebih memilih bermain media social dan game online. Permasalahan tersebut sangat masif dan merata terjadi hampir di setiap lingkungan mulai dari pedesaan apalagi perkotaan (Pramujiono dkk, 2020). Upaya penyadaran tersebut bisa dilakukan dengan banyak cara yang salah satunya yaitu dengan pendampingan remaja santri sebagai wujud pelaksanaan pengabdian dan kepedulian kepada masyarakat (Kasanova \& Zuhri, 2018). Berangkat dari latar belakang tersebut diadakanlah program pendampingan pelatihan MC (Master of Ceremony) yang dilaksanakan di Pondok Pesantren Tarbiyatus Sholihin Kuningan Kanigoro Blitar. Pondok Pesantren yang terletak di Kabupaten Blitar ini dijadikan objek penelitian tindakan karena dari pengamatan awal dipandang memenuhi unsur permasalahan yang bersesuaian dengan latar belakang yang telah disampaikan sebelumnya.

Seiring dengan meningkatnya kualitas pelayanan, kemampuan MC memiliki peran penting dalam kegiatan hiburan maupun acara resmi. Penyelenggaraan acara resmi pada dasarnya merupakan salah satu bentuk pelayanan, baik pelayanan antar pegawai dalam organisasi maupun pelayanan bagi pihak luar organisasi (Darmuki dkk, 2019). Ketika berlangsung suatu kegiatan maka terjadi interaksi antar aparat kantor. Dalam interaksi tersebut terjadi komunikasi interpersonal yang diwadahi dalam sebuah acara resmi. Dalam hal ini sangat membutuhkan kemampuan petugas MC untuk mempersiapkan acara tersebut dan memandu kelancaran acara. Pada akhirnya kelancaran penyelenggaraan 
tersebut akan memberi kesan profesionalitas dan nama baik lembaga (Sulastriana dkk, 2018).

\section{MASALAH}

Kemampuan intelektual seseorang tidak bisa menjamin kesuksesan seseorang tersebut, namun bagaimana mereka bisa "menjual" diri mereka kepada publik. Kemampuan "menjual" ini tidak hanya tergantung pada cara berkomunikasi di depan publik tetapi juga bagaimana seseorang bisa membawa diri mereka agar bisa diterima oleh publiknya (Putra, 2020). Pelatihan ini sengaja dipilih karena diharapkan akan dijadikan pemicu semangat santri untuk mau belajar dan berlatih mempersiapkan dirinya tampil di acara pondok pesantren bahkan di masyarakat. Dengan belajar bersama berbasis proses di pelatihan MC dan ikut mempraktekkannya di depan teman-teman dengan mendapat gojlokan-gojlokan dari teman-temannya menambah sifat percaya diri santri ketika tampil di masyarakat. Maka dari persoalan tersebut peneliti lebih memfokuskan program pada "Pendampingan Pelatihan Speakepreneur dan MC di Pondok Pesantren Tarbiyatus Sholihin Kuningan Kanigoro Blitar“

\section{METODE PELAKSANAAN}

Khayalak sasaran yang terlibat dalam kegiatan pengabdian kepada masyarakat ini adalah santri Pondok Pesantren Tarbiyautus Sholihin di Kuningan Kanigoro Kabupaten Blitar sejumlah 20 orang peserta. Kegiatan pengabdian kepada masyarakat ini dilakukan dengan menerapkan beberapa metode sebagai berikut :

1. Ceramah dan tanya jawab

Metode ini digunakan untuk memberikan pembekalan materi terkait MC dan speakerpreneur meliputi: definisi dan arti pentingnya $\mathrm{MC}$ dan speakerpreneur, ruang lingkup MC dan speakerpreneur, kualifiksi MC dan speakerpreneur, keterampilan dan tugas MC, dan teknis speakerpreneur, dilanjutkan sesi tanya jawab. Kegiatan ini bertujuan untuk meningkatkan pemahaman santri agar mempunyai kesadaran pentingnya kegiatan $\mathrm{MC}$ dan speakerpreneur.

2. Demonstrasi

Metode simulasi/demonstrasi digunakan sebagai tahap akhir dari pelatihan MC dan speakerpreneur yaitu berupa praktik langsung dari setiap peserta untuk mendemokan berperan sebagai MC pada suatu acara tertentu dengan pendampingan 
dari pemateri. Masing-masing peserta dipersilahkan memilih acara yang akan dibawakannya sebagai MC, kemudian peserta langsung mempraktikan berbagai materi yang telah disampaikan pemateri tentang berperan sebagai MC yang baik, meliputi penggunaan bahasa, pengaturan suara, sikap, dan aspek lain dari seorang MC. Penampilan peserta sebagai MC secara langsung akan dievaluasi bersama-sama oleh pemateri dengan menerima masukan dari peserta yang lain.

3. Evaluasi

Kegiatan ini dilakukan untuk melihat kemampuan yang dimiliki oleh peserta setelah pelatihan Master of Ceremony dan speakerpreneur selesai. Evaluasi juga dilakukan untuk melihat seberapa besar peningkatan keterampilan peserta dalam meningkatkan keterampilan serta tata cara berbicara di depan forum.

\section{HASIL DAN PEMBAHASAN}

Pelatihan MC dan speakerprenenur dilakukan di Pondok Pesantren Tarbiyatus Sholihin Kuningan Kanigoro Blitar pada hari Minggu, 20 Juni 2021. Peserta pelatihan terdiri atas 20 orang yang merupakan santriwan/santriwati Pondok Pesantren Tarbiyatus Sholihin Kuningan Kanigoro Blitar. Peserta pelatihan dibekali dahulu mengenai teori terkait MC dan speakerprenenur.

Dari serangkaian kegiatan yang tekah dilaksanakan, peserta mengikuti seluruh tahapan kegiatan dengan baik dan penuh antusiasme. Semua peserta berpartisipasi secara aktif dalam praktik MC dan speakerprenenur, termasuk ketika diberikan materi dan tanya jawab mengenai tata cara MC dan speakerprenenur sesuai dengan forum.

Kegiatan dimulai dengan pemberian materi mengenai teori dan tata cara MC dan speakerprenenur sesuai dengan forum. Setelah pemberian materi selesai tim pengabdian masyarakat memberikan kesempatan kepada para peserta untuk membuat naskah pembukaan MC untuk acara hiburan maupun acara resmi dan kemudian para peserta juga diberi kesempatan untuk mempraktikkannya di depan peserta lain. 


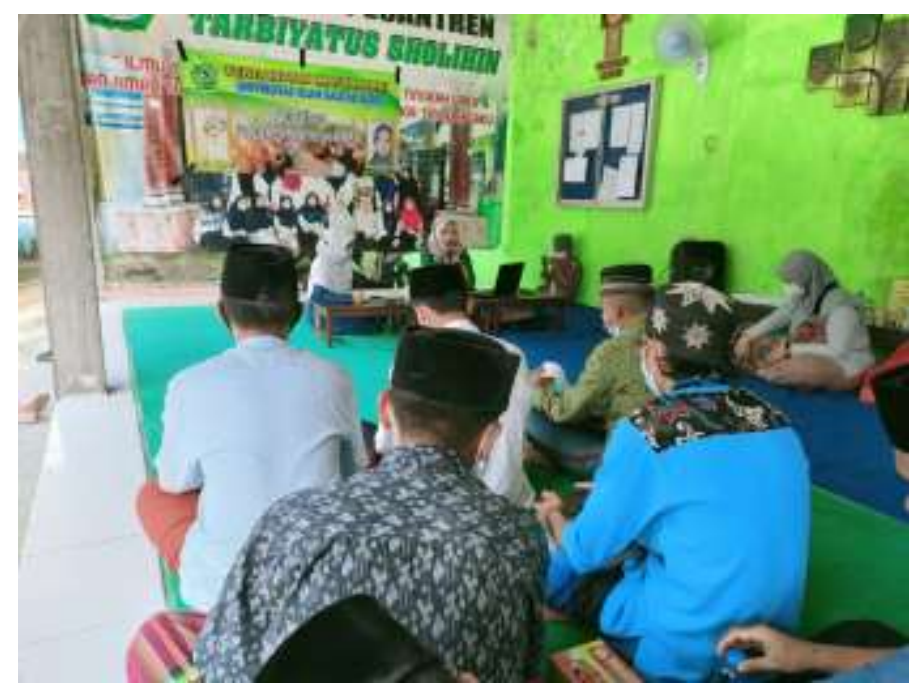

Gambar 1. Penyampaian materi

Sebelum kegiatan berakhir, peserta pengabdian masyarakat diberikan angket untuk melihat seberapa paham dan pengetahuan peserta tentang teori dan tata cara MC dan speakerprenenur setelah menerima materi dan praktik secara langsung. Kemudian para peserta juga diberikan waktu untuk bertanya kepada tim pengabdian apabila ada hal yang kurang dipahami selama proses kegiatan berlangsung.
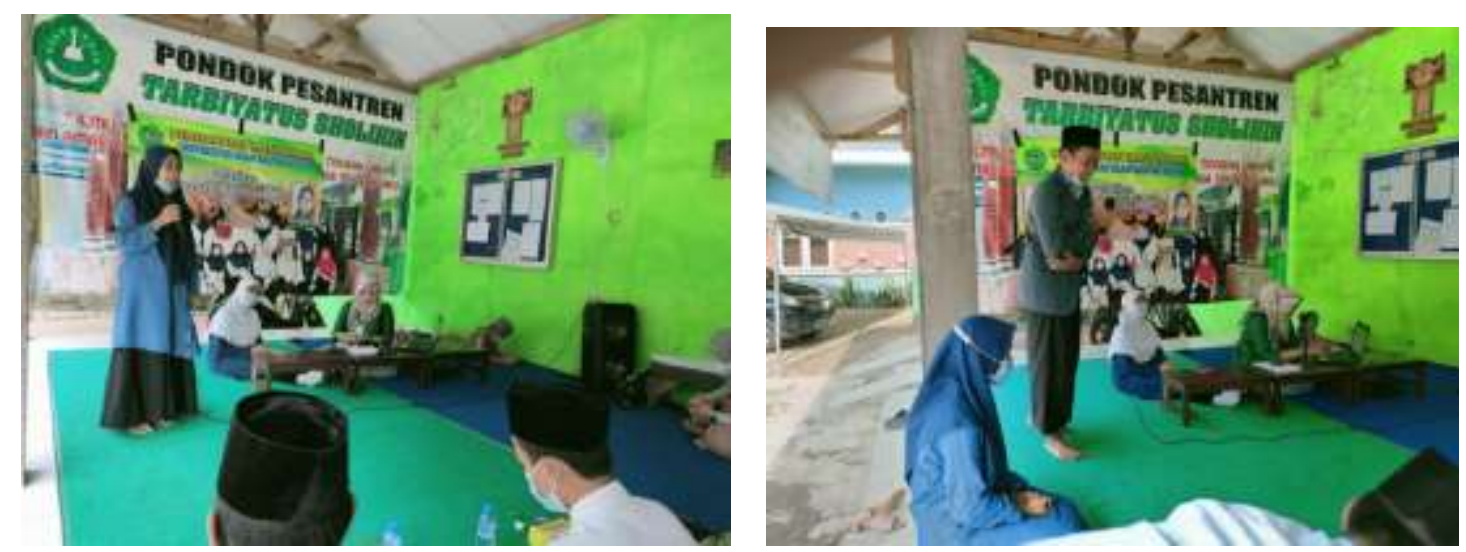

Gambar 2. Kegiatan praktik MC

Antusiasme peserta pengabdian tidak hanya sampai pada tahap berakhirnya kegiatan pengabdian $\mathrm{MC}$ dan speakerprenenur ini, akan tetapi para santriwan/santriwati juga berharap bahwa kegiatan seperti ini lebih sering diadakan di lingkungan Pondok Pesantren. 
Evaluasi dalam pengabdian ini dilakukan untuk melihat seberapa besar peningkatan pemahaman peserta dalam pelatihan MC dan speakerprenenur melalui angket penilaian akhir (post-test).

Tabel 1. Angket Pengabdian Masyarakat Pendampingan Pelatihan Speakerpreneur dan

\begin{tabular}{|c|c|c|c|c|c|}
\hline \multirow{3}{*}{ No } & \multirow{3}{*}{ PERNYATAAN } & & & & \\
\hline & & \multicolumn{4}{|c|}{ PRESENTASE } \\
\hline & & SS & $\mathbf{S}$ & TS & STS \\
\hline 1 & $\begin{array}{l}\text { Kegiatan pengabdian masyarakat melalui } \\
\text { pelatihan MC di Ponpes Tarbiyatus } \\
\text { Sholihin yang dilakukan oleh Tim } \\
\text { Universitas Islam Balitar berjalan dengan } \\
\text { lancar dan saya merasa puas dengan } \\
\text { kegiatan ini }\end{array}$ & $25 \%$ & $75 \%$ & - & - \\
\hline 2 & $\begin{array}{l}\text { Kegiatan pengabdian masyarakat yang } \\
\text { dilaksanakan oleh Tim Pengabdian } \\
\text { Universitas Islam Balitar melalui pelatihan } \\
\text { MC berjalan sesuai dengan harapan saya }\end{array}$ & $25 \%$ & $75 \%$ & - & - \\
\hline 3 & $\begin{array}{l}\text { Anggota pengabdian yang terlibat dalam } \\
\text { kegiatan pengabdian masyarakat melalui } \\
\text { pelatihan MC ini memberikan pengarahan } \\
\text { dengan jelas }\end{array}$ & $30 \%$ & $70 \%$ & - & - \\
\hline 4 & $\begin{array}{l}\text { Keluhan/pertanyaan/masalah yang saya } \\
\text { ajukan ditindaklanjuti dengan baik oleh } \\
\text { anggota pengabdian }\end{array}$ & $40 \%$ & $55 \%$ & $5 \%$ & - \\
\hline 5 & $\begin{array}{l}\text { Saya merasa senang apabila kedepannya } \\
\text { kegiatan seperti ini diadakan kembali dan } \\
\text { saya akan mengikutinya kembali }\end{array}$ & $55 \%$ & $45 \%$ & - & - \\
\hline
\end{tabular}

Sumber : Pengabdian, 2021

Berdasarkan tabel di atas dapat dijelaskan sebagai berikut :

1. Kegiatan pengabdian berjalan lancar dan peserta pengabdian merasa puas dengan kegiatan pengabdian masyarakat melalui pelatihan MC di Ponpes Tarbiyatus Sholihin yang dilakukan oleh Tim Universitas Islam Balitar. Hal ini dibuktikan dengan hasil angket yaitu sebanyak 25\% Sangat Setuju dan sebesar 75\% Setuju.

2. Kegiatan pengabdian masyarakat yang dilaksanakan oleh Tim Pengabdian Universitas Islam Balitar melalui pelatihan MC berjalan sesuai dengan harapan 
peserta. Hal ini dibuktikan dengan hasil angket yaitu sebanyak 25\% Sangat Setuju dan sebesar $75 \%$ Setuju.

3. Anggota pengabdian yang terlibat dalam kegiatan pengabdian masyarakat melalui pelatihan MC ini memberikan pengarahan dengan jelas. Hal ini dibuktikan dengan hasil angket yaitu sebanyak 30\% Sangat Setuju dan sebesar 70\% Setuju.

4. Keluhan/pertanyaan/masalah yang peserta ajukan ditindaklanjuti dengan baik oleh anggota pengabdian. Hal ini dibuktikan dengan hasil angket yaitu sebanyak $40 \%$ Sangat Setuju dan sebesar 55\% Setuju. Akan tetapi sebanyak 5\% menjawab Tidak Setuju, oleh karena itu kedepannya tim pengabdian akan berusaha untuk lebih responsif terhadap pertanyaan maupun permasalahan peserta pengabdian.

5. Para peserta merasa senang apabila kedepannya kegiatan seperti ini diadakan kembali dan akan mengikutinya kembali. Hal ini dibuktikan dengan hasil angket yaitu sebanyak 55\% Sangat Setuju dan sebesar 45\% Setuju.

\section{KESIMPULAN}

Kegiatan pengabdian masyarakat ini dipandang cukup berhasil menambah keberanian dan percaya diri santri-santri Pondok Pesantren Tarbiyatus Sholihin ketika tampil MC di acara-acara pondok maupun acara di luar kegiatan pondok, pasalnya terdapat banyak peningkatan yang terjadi pada mereka. Dalam program ini juga banyak terjadi kerjasama dan komunikasi yang baik antara anggota pengabdian dengan pengasuh pondok, pengurus pondok, kepala Pondok Pesantren Tarbiyatus Sholihin dan para santri.

\section{UCAPAN TERIMA KASIH}

Anggota tim pengabdian mengucapkan terimakasih kepada Universitas Islam Balitar Blitar yang telah memberikan dana sehingga dapat terlaksananya kegiatan pengabdian kepada masyarakat ini. Kemudian tak lupa kami juga berterimakasih kepada pengurus Pondok Pesantren yang telah dengan senang hati memberikan ijin untuk dilakukannya kegiatan ini serta kepada peserta yaitu santri Pondok Pesantren Tarbiyatus Sholihin yang dengan antusias mengikuti kegiatan pengabdian ini.

\section{DAFTAR PUSTAKA}

Darmuki, A., Sholehuddin, M., Hidayati, N. A., \& Sutrimah, S. (2019). Pelatihan MC dan Protokoler Menggunakan Metode Drill Practice dengan Media Audio Visual pada Pemuda Karang Taruna. J-ABDIPAMAS (Jurnal Pengabdian Kepada Masyarakat), 3(1), 37-46. 
Hutomo, A. (2019). Pengaruh Pelatihan Teknik Announcing Terhadap Peningkatan Kualitas Pemandu Acara (MC) Bagi Remaja Kampung Cerdas. Jurnal Komunikasi, 10(1), 83-88.

Kasanova, R., \& Zuhri, M. D. (2018). Pelatihan Keterampilan Master Of Ceremony Bagi Kelompok Remaja Masjid Al-Istikmal Pademawu Sebagai Peluang Usaha di Bidang Jasa. LOYALITAS, Jurnal Pengabdian Kepada Masyarakat, 1(2), 157-167.

Pramujiono, A., Suhari, S. H., Rachmadtullah, R., Indrayanti, T., \& Setiawan, B. (2020). Kesantunan Berbahasa, Pendidikan Karater, Dan Pembelajaran Yang Humanis. Indocamp.

Putra, T. P. (2020). MC Pelatihan Soft Skill Bagi Mahasiswa ISI Yogyakarta.

Sulastriana, E., Hartati, M., \& Yuda, R. K. (2018). Pelatihan Memandu Acara pada Siswa SMP Pancasila Sungai Kakap. GERVASI: Jurnal Pengabdian kepada Masyarakat, 2(1), 1-11.

(C) 2021 by authors. Content on this article is licensed under a Creative Commons Attribution 4.0 International license. (http://creativecommons.org/licenses/by/4.0/). 